\title{
Research on Communication Products Diffusion in China Using Cellular Automata
}

\author{
Fang Ma \\ School of Economics and Management, Nanchang Hang Kong University \\ 696 Fenghe South Avenue, Nanchang 330063, China \\ E-mail: mf1505@126.com \\ School of International Business Administration, Shanghai University of Finance and Economics \\ 777 Guoding Road, Shanghai 200433, China \\ E-mail: mf1505@126.com \\ Gangling Chao \\ School of International Business Administration, Shanghai University of Finance and Economics \\ 777 Guoding Road, Shanghai 200433, China \\ E-mail: chaogl@163.com
}

Received: December 15, 2010 Accepted: January 10, 2011 doi:10.5539/ibr.v4n2p147

The research is financed by Graduate Innovation Foundation Project of Shanghai University of Finance and Economics. No. CXJJ-2009-319

\begin{abstract}
Based on cellular automata (CA), the diffusion of communication products, namely the mobile phone (MP) and the landline telephone (LT), were modeled and simulated. The ordinary least squares (OLS) procedure and nonlinear regression method were carried out to estimate the diffusion parameters. The predicted results were compared with the actual data. It is found that: (1) the diffusion processes of mobile phone and landline telephone were successfully examined using cellular automata method, (2) the predicted results of mobile phone and landline telephone show four stages of the product life cycle, (3) the present situation of mobile phones in China is at the fast growth stage and the present situation of landline telephone is at the maturity stage, (4) the market of mobile communication is growing fast and has a brighter future and the landline communication market is meeting great challenges. The future competition will be more serious between the mobile communication and the landline communication. Both of them can benefit from introduction of advanced technology and new services because such a strategy has the potential to convert some consumers of one of communications into another communications. As for the whole communications, the innovation of technology and services will be generated and introduced into the industry of communications to drive the market.
\end{abstract}

Keywords: Diffusion, Cellular Automata, Simulation, Mobile Phone, Landline Telephone

\section{Introduction}

With the rapid growth of economy, China has become one of the world's largest communications markets. The communication industry can be classified by two types: mobile communications and telecommunications, and the communication products are mobile phone (MP) and landline telephone (LT), respectively. With the liberalization and deregulation of the operators in communications market, the diffusion process and development trend of the two communications has been gained great interest and significance.

Since innovation diffusion theory was introduced to the marketing studies in the mid-1960s, research among consumer behavior, marketing management, and marketing science has resulted in a lot of literatures (Arndt, 1967; Frank et al., 1964; King, 1963; Robertson, 1967; Silk, 1966). Traditionally, diffusion was defined as "the process by which an innovation is communicated through certain channels over time among the member of a social system" (Rogers, 1995). Diffusion theory is frequently looked to for guidance on the dissemination of new technologies, new 
products, new services, and new regulatory initiatives (Gatignon and Robertson, 1985). The research in literatures on modeling of the new product or innovation diffusion offered a lot of frameworks for the study of diffusion of information, ideas, and products. The details of those diffusion models in this area are available in many articles (Mahajan and Muller, 1979; Sultan et al., 1990; Mahajan et al., 1990; Parker, 1994; Hauser et al., 2006; Meade and Islam, 2006).

Owing to the complexity of consumer behavior, the diffusion of new product based on adoption decision of consumers through social interactions among consumers can be considered a complex system problem. One of appropriate and convenient technique to model such complex systems is cellular automata (CA), which was described in detailed in some literatures (Wolfram, 1983; Wolfram, 1984; Chopard and Droz, 1998). The marketing sciences have recently exhibited an increasing interest in diffusion research using cellular automata method. Goldenberg et al. (2001a,b; 2002) examined the effects on new product growth of homogeneous and heterogeneity markets and the process of word-of-mouth and the reason for a major slump in cross-market sales through cellular automata. The models of emergence of innovations (Goldenberg and Efroni, 2001) and the resistance to innovations (Moldovan and Goldenberg, 2004) were established and simulated. The early success of new product was also predicted through the spatial data of sales based on cellular automata (Garber et al., 2004). Cellular automata was also used to simulate technology diffusion of internet (Fang et al., 2007) and market diffusion of new products and new services (Ma et al., 2008, 2009).

In order to reveal the underlying process of communications growth and to analyze the present and future market of communications, a cellular automata model was constructed to capture the complex diffusion dynamics and enable an in-depth analysis of the growth. The diffusion coefficients of mobile phones and landline telephones were estimated and their diffusion processes were simulated by cellular automata. The empirical evidences and predictions of the diffusion of communication products including mobile phones and landline telephones were provided in this paper.

The rest of this article continues as follows. Firstly, we proposed a diffusion model based on cellular automata. Secondly, the method and process of the simulation were presented. Thirdly, the diffusion processes of mobile phone and landline telephone were explored. Finally, we concluded by discussing the theoretical and practical implications.

\section{The Cellular Automata Methodology}

We begin our analysis by using a cellular automata methodology on the communication product diffusion. The cell space is the system of the communications diffusion including ten thousands cells. Each customer of the communication products or potential customer is a cell in the cell space which is the system of the communication products diffusion. There are two states which are customer (receiving the value of 1) or non-customer (receiving the value of 0 ). The state of the center cell at $t$ depends on the state of eight neighbors at $(t-1)$. Each customer can always be a customer after the use in the whole communication product diffusion process. The premise of the Bass model (1969) is used as the evolution rule $R$ of cellular automata

$$
P(t+1)=p+\frac{q}{m} Y(t)
$$

where $p$ is the innovation coefficient and $q$ is the imitation coefficient, and $P$ is the transfer probability from non-customer to customer. Each individual adoption probability is calculated by evolution rule at each cellular automata evolution step (CAES). $Y(t)$ is the cumulative number of previous customers at time $t$.

Simulations are implemented by calculating evolution rules of the communication products diffusion of both mobile phone (MP) and landline telephone (LT). The diffusion parameters are estimated by carrying out the ordinary least squares (OLS) procedure and nonlinear regression method by manipulating the Bass model (Bass, 1969). The data of customers of mobile phone and landline telephone come from Development Research Center of the State Council of P.R. China.

\section{Results and Discussions}

\subsection{The diffusion of mobile phone}

The diffusion parameters of the CA model of mobile phone (MP) are estimated using the actual annual data based on an OLS procedure, and the results are $p=0.0056442, q=0.29293, m=1.2482 \times 10^{5}$. The predicted diffusion processes of MP in different CAES are shown in Figure 1. The diffusion results of the number of customers and cumulative number of customers of mobile phone are displayed in Figure 2 and Figure 3.

From Figure 1, it can be seen that: in the beginning, mainly due to external influences, diffusion of MP is happened evenly throughout the space, while in the later, mainly due to internal influences, diffusion of MP is regional 
gathering.

From Figure 2 and Figure 3, it is found that: (1) the predicted results of the number of customers and cumulative number of customers of mobile phone show a bell-shaped curve and an S-shaped curve, respectively, (2) the predicted results of the number of customers and cumulative number of customers of mobile phones display the four stages (introduction stage, growth stage, maturity stage, and decline stage) of the life cycle of a new product, (3) the present situation of mobile phone in China is in the period of growth stage because the actual annual customer number of mobile phone is growing very fast and will reach the peak in the near future, although a steeper of fluctuation from 2003 to 2005 can be found, (4) with the market of mobile phone fast growing, advanced technology and new service will be created and introduced into the industry of mobile phone to drive the market into the period of maturity stage.

\subsection{The diffusion of landline telephone}

The estimated results of the diffusion parameters of the CA model of landline telephone (LT) are $p=0.0017796$, $q=0.30808, m=6.4671 \times 10^{4}$. The diffusion results of the number of customers and cumulative number of customers of landline telephone are displayed in Figure 4 and Figure 5.

From Figure 4 and Figure 5, it can be seen that: (1) the predicted results of the number of customers and cumulative number of customers of landline telephone show a bell-shaped curve and an S-shaped curve, respectively, (2) the predicted results of the number of customers and cumulative number of customers of landline telephone display the four stages (introduction stage, growth stage, maturity stage, and decline stage) of the life cycle of a new product, (3) the present situation of landline telephone in China is in the period of maturity stage because the actual annual customer number of landline telephone have already reached the peak of the predicted curve (See Figure 4), (4) the market of landline telephone is going to enter the decline stage and gradually be out of the communications market, if the innovation of advanced technology and new services can not be involved in the landline telephone communication.

\section{Conclusions}

In this article, cellular automata method was used to model and simulate the communication products diffusion of mobile phone and landline telephone. The ordinary least squares (OLS) procedure and nonlinear regression method were carried out to estimate the diffusion parameters. The predicted results were compared with the actual data. Some significant conclusions can be made as follows.

Firstly, the diffusion processes of mobile phone and landline telephone in China were successfully examined using cellular automata method.

Secondly, the predicted results of mobile phone and landline telephone show four stages of the product life cycle, namely the introduction stage, the growth stage, the maturity stage, and the decline stage.

Thirdly, the present situation of mobile phone in China is at the fast growth stage, and the annual customer increments of mobile phone will reach the peak in the near future. With the market of mobile phone fast growing, advanced technology and new service will be created and introduced into the industry of mobile phone to drive the market into the period of maturity stage

Fourthly, the present situation of landline telephone in China is at the maturity stage, and the annual customer increments of landline telephone have already reached the peak of the predicted curve. The market of landline telephone is going to enter the decline stage and gradually be out of the communications market, if the innovation of advanced technology and new services can not be involved in the landline telephone communication

Finally, the results indicated that the market of mobile communication is growing fast and has a brighter future and the landline communication market is meeting great challenges. The future competition will be more serious between the mobile communication and the landline communication. Both of them can benefit from introduction of advanced technology and new services because such a strategy has the potential to convert some consumers of one of communications into another communications. As for the whole communications, the innovation of technology and services will be generated and introduced into the industry of communications to drive the market.

\section{References}

Arndt, J. (1967). Role of Product-Related Conversations in the Diffusion of a New Product. Journal of Marketing Research, 4 (August), 291-295.

Bass, F. M. (1969). A New Product Growth for Model Consumer Durables. Management Science, 15 (5), 215-227.

Chopard, B. and Droz, M. (1998). Cellular Automata Modeling of Physical Systems. Cambridge University Press. 
Fang, L., Gong, X.G. and Xiao, R.B. (2007). Modeling diffusion of innovations with cellular Automata. System simulation technology, 3(2), 82-89 (In Chinese).

Garber, T., Goldenberg, J., Libai, B. and Muller, E. (2004). From Density to Destiny: Using Spatial Dimension of Sales Data for Early Prediction of New Product Success. Marketing Science, 23(3), 419-428.

Gatignon, H. and Robertson, T. S. (1985). A Propositional Inventory for New Diffusion Research. Journal of Consumer Research, 11(4), 849-867.

Goldenberg, J. and Efroni, S. (2001). Using Cellular Automata Modeling of the Emergence of Innovations. Technological Forecasting and Social Change, 68 (3), 293-308.

Goldenberg, J., Libai, B. and Muller, E. (2001a). Using Complex Systems Analysis to Advance Marketing Theory Development: Modeling Heterogeneity Effects on New Product Growth through Stochastic Cellular Automata. Academy of Marketing Science Review, 2001(2001), 1-19.

Goldenberg, J., Libai, B. and Muller, E. (2001b). Talk of the Network: A Complex Systems Look at the Underlying Process of Word-of-Mouth. Marketing Letters, 12 (3), 211- 223.

Goldenberg, J., Libai, B. and Muller, E. (2002). Riding the saddle: How cross-market communications can create a major slump in sales. Journal of Marketing, 66(2), 1-16.

Hauser, J., Tellis, G.J. and Griffin, A. (2006). Research on Innovation: A Review and Agenda for Marketing Science. Marketing Science, 25(6), 687-717.

Ma, F., Luo, M. and Yang, H.J. (2008). Simulation of Market Diffusion of New Product Based on Cellular Automata. In: 2008 Global Marketing Conference on Marketing in the Dynamic Global World. March, 20-23, Shanghai, China.

Ma, F., Luo, M., Peng, D.Y. and Deng, J. (2009). Simulation of New Service Product Diffusion on Cellular Automata. Journal of Chinese Marketing, 2(1), 88-94.

Mahajan, V. and Muller, E. (1979). Innovation Diffusion and New Product Growth Models in Marketing. Journal of Marketing, 43(4), 55-68.

Mahajan, V., Muller, E. and Bass, F.M. (1990). New Product Diffusion Models in Marketing: A Review and Directions for Research. Journal of Marketing, 54(1), 1-26.

Meade, N. and Islam, T. (2006). Modelling and forecasting the diffusion of innovation-A 25-year review. International Journal of Forecasting. 22(3), 519-545.

Moldovan, S. and Goldenberg, J. (2004). Cellular Automata Modeling of Resistance to Innovations: Effects and Solutions. Technological Forecasting and Social Change, 71 (5), 425-442.

Parker, Philip M. (1994). Aggregate diffusion forecasting models in marketing: A critical review. International Journal of Forecasting, 10 (2), 353-380.

Rogers, E. M. (1995). Diffusion of Innovations. (4th Ed.). New York: The Free Press.

Silk, Alvin J. (1966). Overlap Among Self-Designated Opinion Leaders: A Study of Selected Dental Products and Services. Journal of Marketing Research, 3 (August), 255-259.

Sultan, F., Farley, J. U. and Lehmann, D. R. (1990). A Meta-Analysis of Applications of Diffusion Models. Journal of Marketing Research, 27(1), 70-77.

Wolfram, S.(1983). Statistical Mechanics of Cellular Automata. Reviews of Modern Physics, 55 (3), 601-644.

Wolfram, S.(1984). Cellular automata as models of Complexity. Nature, 311(4), 419-424. 


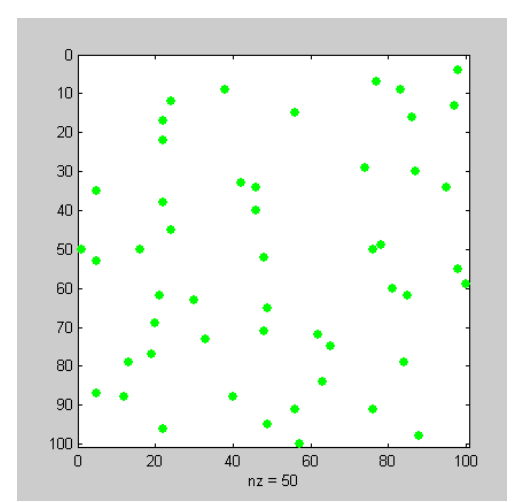

(a) CAES 1

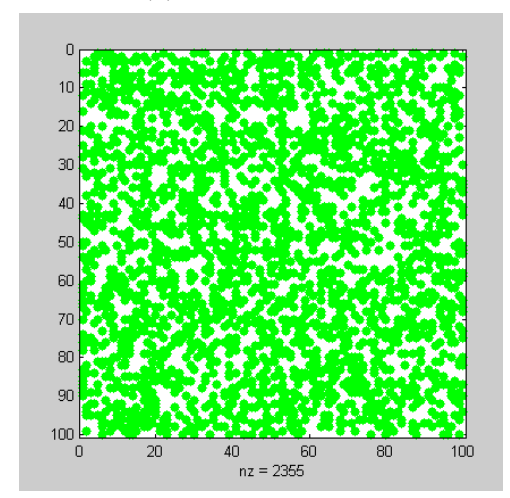

(c) CAES 10

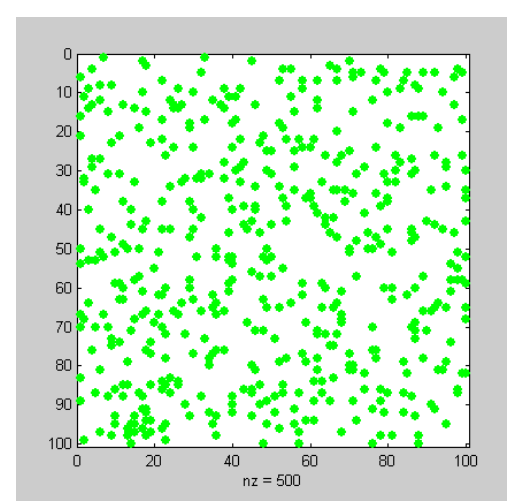

(b) CAES 5

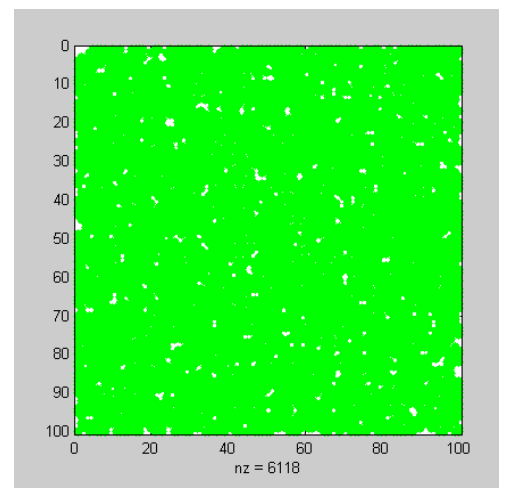

(d) CAES 15

Figure 1. Diffusion process of mobile phones under different CAES.

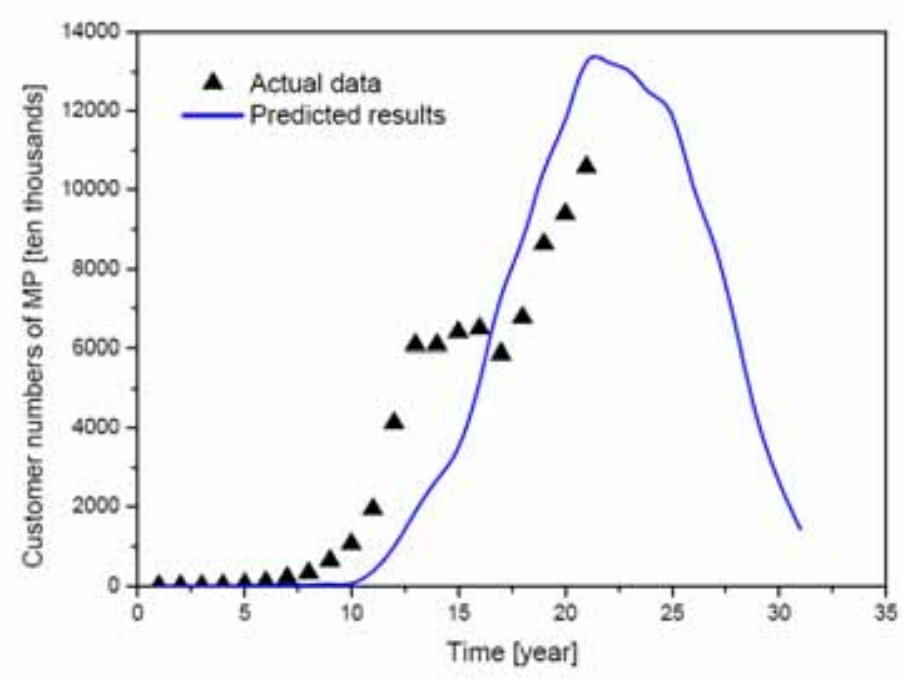

Figure 2. Customer numbers of mobile phone 


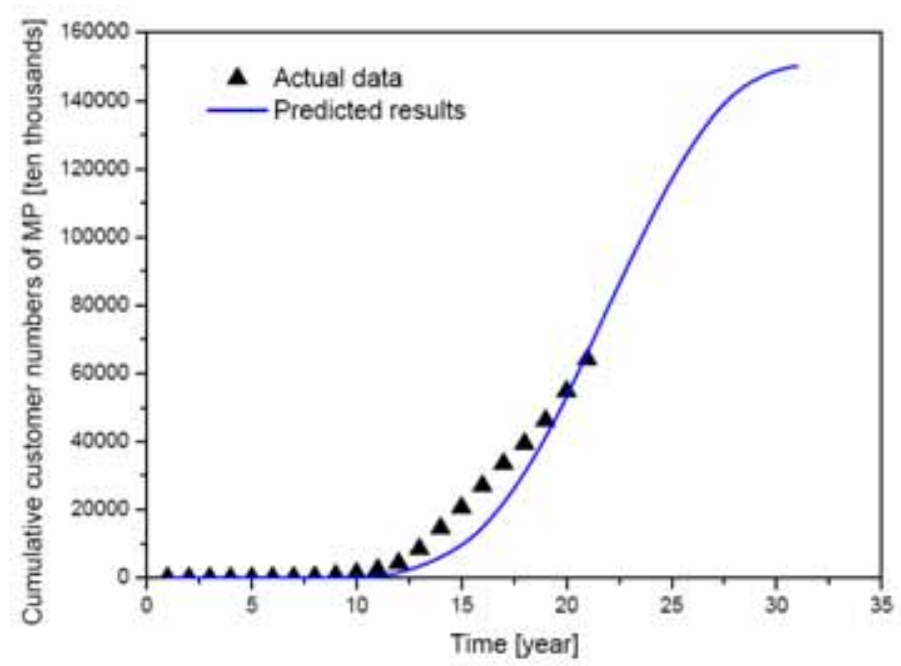

Figure 3. The cumulative number of customers of mobile phone

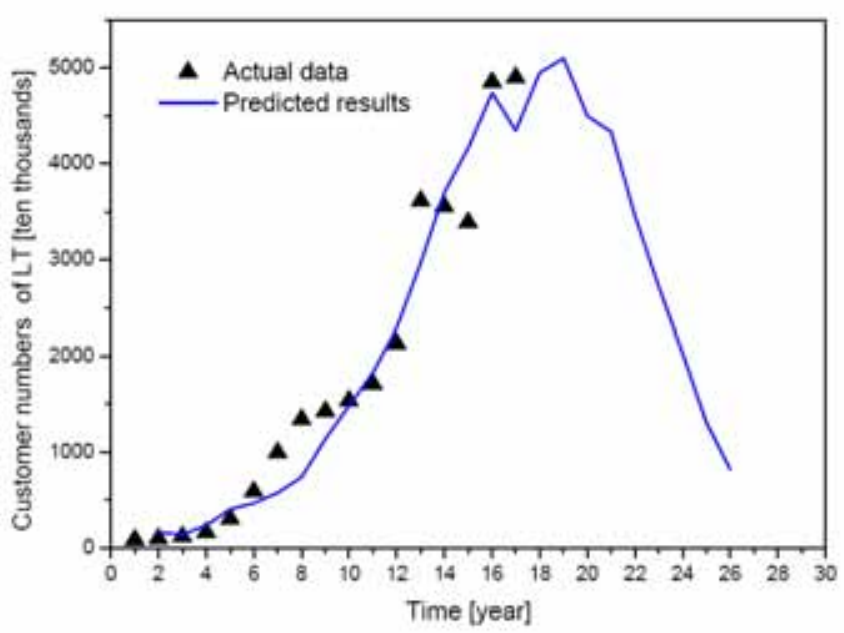

Figure 4. The number of customers of landline telephone

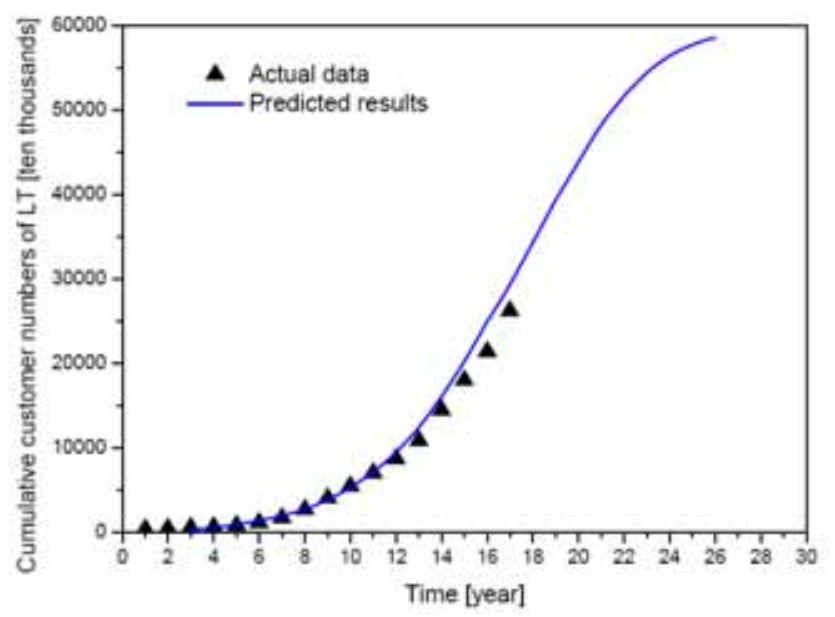

Figure 5. The cumulative number of customers of landline telephone 